\title{
A representação social do preconceito racial para professores negros da UFMG
}

Beatriz Lopes Falcão*

Andrea Cristina Cirino**

* Mestre em Educação pela Universidade Federal de Minas Gerais. Professora no curso de especialização em Gestão Escolar (UFMG/MEC). Bolsista do Ipea/Anped.

E-mail:

falcao.b@gmail.com

** Mestre em Música pela Universidade Federal de Minas Gerais. E-mail: accirino@terra.com.br
Resumo: 0 presente artigo se propôs a analisar o sentido do preconceito racial para docentes negros da Universidade Federal de Minas Gerais e os conteúdos de representação social em que se apoiavam as práticas com esse cunho. Para tal, utilizou-se como material de investigação 16 entrevistas publicadas por Praxedes et al. (2009) no livro Memórias e percursos de professores negros e negras na UFMG. Considerando as atuais normas sociais contra esse preconceito, identificou-se ainda sua presença, tanto de forma explícita como velada, no cotidiano desses professores. Constatou-se que embora os docentes gozassem de status socioeconômico e educacional, isso não foi suficiente para isentá-los do confronto com essa prática. Concluiuse que a ilegalidade do preconceito racial não extinguiu os seus conteúdos representacionais, que ainda se mantêm conservados e circulantes na sociedade brasileira.

Palavras-chave: Preconceito racial. Representação social. Professores negros. UFMG. 
INTRODUÇÃO

A polarização racial parece persistir no Brasil contemporâneo. Da pósescravatura aos dias atuais é possível perceber uma sociedade que ainda convive com essa questão, na qual hierarquizações sociais, preconceitos e discriminações ainda remetem a construções sociais derivadas do conceito de raças e da diferenciação inata entre elas. Embora não exista, na atualidade, sustentação científica para distinções biológicas entre a raça humana, a classificação racial (apoiada nas características fenotípicas dos indivíduos, entre elas a cor da pele) perdura no senso comum e continua produzindo desigualdades (GUIMARÃES, 2002), implicando em um “[...] cenário sinistro de discriminação e exclusão de pessoas negras” (LIMA; VALA, 2004, p. 407).

Para a coibição de práticas preconceituosas foram promulgadas leis, como a no 7.716/89, que “[...] define os crimes resultantes de preconceito de raça ou de cor" (BRASIL, 1989). Todavia, estudos com essa temática (CAMINO et al., 2001; PEREIRA; TORRES; ALMEIDA, 2003; LIMA; VALA, 2004; CABECINHAS; AMÂNCIO, 2004; SANT'ANA, 2005) constatam que apesar desses avanços da legislação, práticas de cunho preconceituoso ainda permanecem, coexistindo com discursos de uma suposta "democracia racial". Nesse sentido, manifestações explícitas de preconceito têm sido minoradas; contudo, novas formas vêm sendo desenvolvidas, expondo uma transformação nas manifestações do racismo (LIMA; VALA, 2004), mas não no seu conteúdo. Na opinião de Cabecinhas e Amâncio (2004, p. 140): “O facto da hierarquização racial ter sido banida do discurso público não exclui comportamentos e percepções racistas. Atentas às novas normas sociais, as pessoas têm 0 cuidado de velar os seus discursos [...]".

No caso brasileiro, em virtude da composição miscigenada da população, o preconceito racial é muitas vezes "camuflado" sob a forma de preconceito socioeconômico (CAMINO et al., 2001). De acordo com Dahia (2008, p. 699), “[...] os brasileiros não se consideram racistas e gostam de ostentar uma imagem de gente sem preconceito afeita à mistura racial; por outro, quando são sondados sutilmente, fornecem indicadores que apontam para um preconceito racial latente". Estudos como os de Venturi e Paulino (1995), Camino et al. (2001) e de Pereira, Torres e Almeida (2003) apontam que a maioria dos brasileiros não se julga racista/ preconceituosa, mas avalia que a sociedade o é. 
0 preconceito racial aqui manifesto percorre caminhos mais sutis, sendo denominado como racismo cordial (CAMINO et al., 2001; LIMA; VALA, 2004), no qual a discriminação contra os negros se expressa nas relações pessoais “[...] através de piadas, ditos populares e brincadeiras de cunho racial” (LIMA; VALA, 2004, p. 407). O discurso jocoso desse tipo de racismo é igualmente pernicioso à equidade racial como qualquer outro, considerando que: "Tornar alguém ou algo risível é destituí-lo de poder, é enfraquecê-lo, é infantilizá-lo" (DAHIA, 2008, p. 705) e assim mantê-lo em um patamar inferior na estrutura social. E como afirmam Camino et al. (2001, p. 22):

Acrescentaríamos que este racismo à brasileira não tem nada de cordial; muito pelo contrário, por ser mascarado, ele é não apenas terrivelmente eficiente em sua função de discriminar as pessoas de cor negra, mas é também, lamentavelmente, muito difícil de erradicar.

É importante destacar que o racismo, o preconceito e a discriminação diferenciam-se em sua conceituação. Nesse sentido,

O racismo constitui-se num processo de hierarquização, exclusão e discriminação contra um indivíduo ou toda uma categoria social que é definida como diferente com base em alguma marca física externa (real ou imaginada), a qual é ressignificada em termos de uma marca cultural interna que define padrões de comportamento (LIMA; VALA, 2004, p. 402).

O preconceito racial associa-se normalmente a uma opinião ou a um julgamento prévio, de cunho negativo, que é feito sobre as pessoas que são da raça negra (SANT'ANA, 2005). E a discriminação se refere à “[...] conduta (ação ou omissão) que viola direitos das pessoas com base em critérios injustificados e injustos, tais como a raça, o sexo, a idade, a opção religiosa e outros" (SANT'ANA, 2005, p. 63, ênfases do autor); ou seja, a atitude discriminatória exterioriza o preconceito e a ideologia racista.

Sendo assim, o racismo é consolidado por meio do preconceito, da discriminação e com o suporte dos estereótipos, que, segundo Silva (2005, p. 24), “[...] têm uma função importante nesse processo, uma vez que é através deles, em grande parte, que as ideologias são veiculadas [...]”. Nesse sentido, "[...] os estereótipos geram os preconceitos, que se constituem em um juízo prévio a uma ausência de real conhecimento do outro".

Diante do interesse pela investigação sobre atitudes raciais e suas diferentes interpretações em relação ao racismo e ao comportamento preconceituoso que abrange a raça e o contexto social, o estudo se propôs a analisar o sentido de preconceito racial para os docentes negros pós-graduados da Universidade 
Federal de Minas Gerais, identificando, portanto, em quais conteúdos de representação social as práticas preconceituosas se apoiavam.

Na perspectiva da sociedade brasileira que torna ilegal o preconceito racial, a teoria das representações sociais torna-se pertinente para guiar a análise dos dados, visto que as novas expressões desse comportamento podem remeter a representações sociais que não foram superadas pela coerção legal nem pela veiculação científica da inexistência de diferenças significativas entre as raças. Desse modo, a relação entre indivíduo e sociedade se constitui em um desafio relevante para a psicologia social (JODELET, 2005; JOVCHELOVICH, 2004; MOSCOVICl, 2003), capaz de nos orientar para a interpretação de novas informações do mundo cotidiano.

\section{A CONSTRUÇÃO DE SENTIDO NAS REPRESENTAÇÕES SOCIAIS}

Para os pesquisadores dessa área, a conceituação de Denise Jodelet sobre as representações sociais torna-se um exemplo apropriado: “As representações sociais são uma forma de conhecimento socialmente elaborado e compartilhado, com um objetivo prático, e que contribui para a construção de uma realidade comum a um conjunto social" (JODELET ${ }^{1}, 2002$ apud ARRUDA, 2005, p. 138). Nesse sentido, as representações “[...] implicam um trabalho simbólico que emerge das inter-relações Eu, Outro e objeto-mundo e, como tal, têm o poder de significar, de construir sentido, de criar realidade" (JOVCHELOVICH, 2004, p. 35).

De acordo com a grande teoria proposta por Moscovici (2003), as representações sociais são matizadas por dois processos formadores primordiais: a ancoragem e a objetivação. Nesse sentido, o processo de ancoragem refere-se ao fato de transformar algo estranho em familiar, de senso comum, colocando em funcionamento o mecanismo de classificação e nomeação de coisas. Intrinsecamente ligado ao mecanismo de ancoragem, o processo de objetivação tenta tornar concreto algo que é abstrato, transformando ideias ou conceitos em imagens visíveis e tangíveis (MOSCOVICl, 2003, p. 61). Além de facilitar a comunicação, a objetivação “torna-se a verdadeira essência da realidade" (MOSCOVICI, 2003, p. 71), pois permite domesticar o universo intelectual a partir de um significado próprio de forma que seja possível entendê-lo de forma acessível. Quando uma representação social está objetivada, a sua última etapa é a naturalização, na qual seus conteúdos e suas relações “[...] constituem-se como categorias JODELET, D. Representações sociais: um domínio em expansão. In: representações sociais. Rio de Janeiro: Eduerj, 2002, p. 17-44. (Org.). As 
naturais, adquirindo materialidade. Isto é, os conceitos tornam-se equivalentes à realidade e o abstrato torna-se concreto através da sua expressão em imagens e metáforas" (CABECINHAS, 2004, p. 128).

Decerto, esses processos - ancoragem e objetivação - são dinâmicos, baseados em experiências que consequentemente lidam com o passado. Portanto, nas representações sociais, “[...] a solidez da memória impede de sofrer modificações súbitas, de um lado e de outro, fornece-lhes certa dose de independência dos acontecimentos atuais - exatamente como uma riqueza acumulada nos protege de uma situação de penúria” (MOSCOVICI, 2003, p. 78).

Considerando as opiniões de Lima e Vala (2004, p. 401) quando afirmam que “[...] o preconceito e o racismo parecem ser tão antigos quanto são as relações assimétricas de poder entre os homens e a concomitante necessidade de justificação dessas relações”, buscamos delinear os conteúdos de representações sociais invocados acerca do preconceito racial que permeava as narrativas dos docentes negros analisados, assim como o sentido desse preconceito para eles. De acordo com Vala² (1993 apud CABECINHAS, 2004, p. 130), “[...] nas representações sociais, o estudo dos conteúdos e a sua articulação com contextos históricos e configurações culturais ou ideológicas é um problema nuclear [...]". E conforme Jovchelovitch (2004, p. 37): “É a análise do sentido que pode esclarecer o fato de que diferentes pessoas, em diferentes contextos e tempos, produzem diferentes visões, símbolos e narrativas sobre o que é real”.

\section{MÉtodo}

O estudo, de abordagem qualitativa e com estratégia exploratória, foi conduzido a partir dos suportes da representação social, referindo-se à perspectiva processual de Denise Jodelet, embora não tenha sido possível fazer um trabalho com métodos e técnicas tão diversificados como os dessa autora.

Com base nas proposições da teoria das representações sociais, de Serge Moscovici, Jodelet (2005) enfatiza a importância da veiculação dos discursos dos indivíduos e grupos para a manutenção das representações, além dos documentos e registros que servem para essa manutenção. Nessa perspectiva, optamos por analisar um corpus de entrevistas disponibilizadas

VALA, Jorge. Representações sociais - para uma psicologia social do pensamento social. In: VALA, Jorge; MONTEIRO, Maria Benedicta (Orgs.), Psicologia social. Lisboa: Fundação Calouste Gulbenkian, 1993. 
por Praxedes et al., no livro Memórias e percursos de professores negros e negras na UFMG, publicado em 2009 e parte do projeto realizado pelo Programa Ações Afirmativas da UFMG. O objetivo principal desse Programa foi o de registrar um pouco da história e protagonismo de negros e negras no mundo acadêmico.

Tal opção metodológica é comum em pesquisas sobre representações sociais, uma vez que o discurso veiculado, seja ele midiático, impresso ou oral, pode fornecer dados importantes acerca dos conteúdos de representação social circulantes, assim como sobre o sentido atribuído. A escolha desse material para a análise se referiu à sua originalidade, visto que tornou público os depoimentos de um grupo da raça negra em posições ocupacionais e educacionais incomuns no Brasil; e possibilitava o confrontamento do discurso, veiculado pelo senso comum - que associa o preconceito racial ao socioeconômico e não à raça apenas (GUIMARÃES, 2002) - com as narrativas desses docentes que vivenciaram o preconceito, apesar de estarem em posições sociais que não corroboravam esse senso comum.

Dessa forma, o grupo analisado (que corresponde ao grupo disponibilizado no livro de Praxedes et al.) foi constituído por 16 professores pós-graduados negros integrados à Universidade Federal de Minas Gerais, dentre eles 12 homens e quatro mulheres. Esses professores atuavam em áreas bem diversas da Universidade, como nas de Ciências Humanas e Sociais, Ciências Exatas, Ciências da Vida (Saúde), Literatura e Artes. No período das entrevistas, a quantidade de professores negros na UFMG atingia o número de 26 pessoas, correspondendo a menos de $5 \%$ da população de docentes nessa Universidade (PRAXEDES et al., 2009).

A análise de dados referiu-se ao estudo de seus conteúdos, sob a perspectiva de Bardin (1977), que implicou a compreensão das experiências vivenciadas por professores negros da UFMG. Inicialmente, a análise procedeu, sob a forma descritiva, da identificação e reunião de elementos por categorias que correspondiam ao racismo, preconceito racial e práticas preconceituosas, concernentes às "unidades de significado" (TRINDADE; MENADRO; GIANÓRDOLI-NASCIMENTO, 2007, p. 83-84).

A articulação entre teoria e contexto resultou na estruturação das categorias temáticas e na consequente identificação do preconceito racial na perspectiva de professores negros pós-graduados da UFMG, compreensível pela teoria das representações sociais. 
Reiterando as ideias de Moscovici (2003, p. 61),

No momento em que determinado objeto ou ideia é comparado ao paradigma de uma categoria, adquire características dessa categoria e é reajustado para que se enquadre nela. Se a classificação, assim obtida, é geralmente aceita, então qualquer opinião que se relacione com a categoria irá se relacionar também com o objeto ou com a ideia.

Sob a ótica do contexto sócio-histórico explicitado nas narrativas dos professores, optamos por destacar temáticas acerca do sentido do preconceito racial para esses sujeitos e como eles discursavam diante da constatação dessa prática no meio acadêmico, assim como noutras instâncias socializadoras. Os conteúdos e estereótipos invocados nos exemplos em que o preconceito racial se manifestava também foram objetos da análise.

\section{RESULTADOS E DISCUSSÃO}

\section{O sentido do preconceito racial para os professores negros}

As narrativas dos docentes da UFMG revelaram que o preconceito racial é percebido de maneira diversa entre eles, que implicou desde a inexistência de constrangimento a uma experiência de discriminação em função da raça, que pôde ser associada ao preconceito social.

Dentre os professores, S. C. disse que não se lembrava de ter sofrido constrangimento ou preconceito na Universidade. Em sua opinião, a transparência da discriminação racial é percebida conforme a situação de sociabilidade ${ }^{3}$. R. M. também afirmou não ter tido problemas evidentes de preconceito na Universidade, mas declarou ter experimentado casos explícitos de discriminação na vida cotidiana. Para essa docente: “[...] a questão do negro é atravessada gravemente pela econômica e pelo social"4 e, dessa maneira, esses elementos podem estar concatenados em uma situação de preconceito. Para W. A., que vivenciou situações incômodas acerca do preconceito, "a cor de pele, o fenótipo, a aparência” parecem prevalecer em determinadas circunstâncias, mas a distinção social também pode causar suspeita de preconceito ${ }^{5}$. Em uma perspectiva semelhante às falas dos professores citados, Oliveira e Barreto (2003, p. 196) apontam que “[...] quando se trata de atribuições para as desigualdades raciais existe um

PRAXEDES, V. L.; TEIXEIRA, I. A. C.; SOUZA, A. X.; GONZAGA, Y. M. (Orgs). Memórias e percursos de professores negros e negras da UFMG. Belo Horizonte: Autêntica, 2009, p. 138.

Ibid, p. 123.

Ibid, p. 170-171. 
senso comum bastante arraigado em torno da ideia de que o fator explicativo mais importante é o econômico".

Por outro lado, M. S., M. J. e H. J. relataram que não foram vítimas de preconceito racial. H. J. não comentou nenhum caso específico de discriminação racial na academia. Para ele,

[...] são as dificuldades materiais que trazem os maiores problemas para que as pessoas menos favorecidas consigam ter acesso a uma série de outras coisas, dentre elas a instrução. O fato de ser negro só amplia essas dificuldades”. Contudo, ele reconheceu que

além da discriminação em função das questões materiais, tem o preconceito em função da cor'”. Nesses casos citados, há a crença de que o preconceito racial se soma ao social, mas o racial não se torna a razão principal das discriminações sofridas.

Na opinião de M. S., o racismo existe e pode ser "oculto". No entanto, ele afirmou que mesmo encontrando dificuldades relacionadas à condição socioeconômica em sua trajetória na Universidade, ele teve uma boa relação com pessoas da elite, sem observar rejeição por parte dos colegas brancos. Nesse contexto, a problemática sobre o preconceito referiu-se mais à classe social do que à raça, pois “negro rico não tem problema”, ele expôs. Portanto, o empecilho seria a falta de dinheiro, e não a raça. Para esse professor, diante de um sujeito rico, uma pessoa chega a pensar: “[...] 'aquele nego [sic] chato lá', mas não fala’”.

De modo semelhante, $M$. J. enfatizou que não foi vítima do preconceito racial, mesmo quando rejeitado pelas moças negras nos bailes frequentados na juventude. Ele explicou que o fato de nunca ter sofrido preconceito significa que a discriminação existente especificamente pela raça jamais o prejudicou. Assim, para M. J., o único docente que mencionou ter nascido em "berço de ouro", o problema não consiste em ser negro, mas na consequência ligada à pobreza, que leva o indivíduo a acumular desvantagens pelo despreparo econômico.

Podemos observar que o fato de haver professores que não relataram a vivência de situações de preconceito racial não extingue a percepção do racismo. Nesse aspecto, emergiu o predomínio da questão social, identificando a raça sob a ótica da condição socioeconômica. De modo ambivalente, a negação da discriminação por causa da raça se interligou ao Ibid, p. 69.

Ibid, p. 95.

Ibid, p. 103. 
sucesso, destaque e conquistas - posições consideradas raras para um negro em nossa sociedade. Assim, por serem reconhecidamente competentes em sua área, ou por já terem uma melhor condição familiar de existência (como M. J.), a inexistência de obstáculos relacionados diretamente à raça pode ser considerada exceção.

Para os professores D. F., L. M., L. A., R., T. S. e T. o preconceito racial é latente e tangível e secundariamente se relaciona à condição social. De acordo com R., as pessoas dizem que: “O preconceito não é racial, ele é socioeconômico. Eu não acho que seja. Eu acho que, até certo ponto, é uma coisa, e depois de determinado ponto são duas 9 ." E evidenciou:

Quando sou barrado, eu não sou barrado por causa da minha condição socioeconômica, 10 porque cheguei até lá, apesar dela. Então, tem outro motivo, porque eu chego e o porteiro não me deixa entrar, como é que ele sabe que eu sou pobre? A priori ele não saberia isso nitidamente.

Para T. S. a questão econômica não se resolve independentemente da questão racial no Brasil, sendo necessária uma intervenção do Estado para minimizar esse quadro de desigualdade entre as raças.

Pelo ponto de vista de A. A., mesmo que as discriminações sejam sutis, elas revelam o preconceito que sugere que “[...] aqui não é o seu lugar, por que você está neste lugar?"1" E C. R. pontuou que a discussão não verbalizada sobre a negritude demonstra discriminações veladas e subjetivas. Desse modo, um discurso que represente estereótipos negativos ou ideias de exclusão tornase menos explícito, disfarçando a existência do preconceito.

M. M. assinalou que a questão racial está presente, embora as pessoas tentem ofuscá-la por meio de gestos ou ações. C. H. apontou que, apesar de "carinhoso", o racismo brasileiro é "sacana" e "escalonado", proveniente de uma sociedade "machista" que identifica o povo pelo tom da pele ${ }^{12}$. Ele complementa: “[...] nos escalões mais baixos você vai encontrar o pessoal que carrega mais peso"13.

De acordo com Guimarães ${ }^{14}$ (1999 apud CAMINO et al., 2001, p. 17), “[...] a cor da pele serve ainda como um símbolo da discriminação existente”. Em outras palavras: “[...] quanto mais 'escuro' o indivíduo, maiores são as chances de ele identificar a existência de racismo no Brasil” (OLIVEIRA; BARRETO, 2003, p. 200).

\footnotetext{
Ibid, p. 133.

Ibid, p. 133.

Ibid, p. 29.

Ibid, p. 47.

Ibid, p. 51.
}

14 GUIMARÃES, A. S. A. Racismo e anti-racismo no Brasil. São Paulo: Editora 34, 1999. 
Mesmo com divergências nas vivências e opiniões dos docentes, é possível apreender que o sentido do preconceito, especialmente o racial, para esses professores funciona como um eficaz mecanismo de exclusão social, no qual são reservados aos negros postos menos qualificados e com características subalternas em nossa sociedade. Essa questão é evidente em uma análise dos dados do Instituto Brasileiro de Geografia e Estatística (IBGE, 2010) sobre o acentuado desnível de escolaridade, rendimentos e atividades ocupacionais entre brancos e negros, e como acentuou L. M.: "Nosso sistema de discriminação é mais eficaz que o apartheid da África do Sul”.

Nas falas dos professores, isso é apreendido quando eles discursaram acerca da redução de colegas negros à medida que iam ascendendo na escolarização e também no status ocupacional (professores universitários). S. C. comentou que: "Em Viçosa eu era o único negro. Tinha um outro [...] mas ele era panamenho. Brasileiro eu era o único. Em Campinas também eu era o único. Em Florianópolis também era o único. E lá na França também era o único ${ }^{16 ”}$.

Sobre isso, L. A. também observou: “Durante a graduação, eu era o único estudante negro na sala, e a gente não discutia a questão racial dentro da universidade ${ }^{17}$ ". De modo similar, M. S. e S. C. foram os únicos estudantes negros do curso que realizaram a graduação. L. M. também teve essa percepção: "Na escola pública, onde eu fiz os quatros [sic] primeiros anos, havia mais negros [...] No ginásio eu era a única negra, no segundo grau eu era a única negra, na universidade uma das únicas negras também ${ }^{18}$ ". E T. disparou:

19 Quantos professores negros têm a UFMG? Astrônomos negros conheço dois, mas agora a coisa tem mudado um pouco. Aqui no Departamento [...] alunos negros também são muito poucos. Aqui nós temos muitos negros na população e poucos negros conseguem chegar até a universidade, conseguem ser um professor universitário.

Nesse sentido, podemos refletir que as ideias expostas anteriormente denotam a sub-representação do negro, adaptado ao meio acadêmico como exceção. Considerando a perspectiva representacional, os docentes da UFMG creem de modo unânime na existência do preconceito racial em nossa sociedade, vinculado ou não à classe social. Constatou-se, portanto, que “[...] a discriminação em função da cor da pele continua a se desenvolver", principalmente nos países que praticaram a escravidão negra (CAMINO et al., Ibid, p. 79.

Ibid, p. 141-142.

Ibid, p. 83.

Ibid, p. 76.

Ibid, p. 161. 
2001, p. 17).

VIVENCIANDO O PRECONCEITO RACIAL NO COTIDIANO

Comportamentos orientados pela ideologia racista, manifestados de forma flagrante ou velada (CAMINO et al., 2001; LIMA; VALA, 2004), contribuem para a manutenção da exclusão social dos negros, que em diversas situações cotidianas são tratados como inferiores e não adequados ao lugar que estão, sendo necessário desenvolver estratégias (seja de embate, de espera ou de excelência intelectual) para conseguirem se impor como profissionais qualificados que são, ou como sujeitos com igual valor humano (ELIAS; SCOTSON, 2000). Conforme Dahia (2008, p. 699):

É exatamente em um quadro de relação social que o racismo adquire sentido, pois materializa, na realidade prática, a dessimetria das relações, excluindo e rejeitando, quer consciente, quer inconscientemente, aquele que é identificado como diferente.

De acordo com S. C., a carga negativa histórica sobre os negros dificulta o rompimento das barreiras impostas: “[...] acredito que essa dificuldade histórica que a gente vê relatada em livros, você vencer é difícil quando está embaixo na pirâmide. Por mais garra, por mais força que você tenha, é muito difícil2o". E na opinião de T.

[...] sempre você identifica o preconceito, ele existe e está aí mesmo. Enfim, em ações ou 21 mesmo naquelas coisas veladas de sempre, mas toda a minha vida foi permeada por uma luta muito difícil e que grande parte das dificuldades era pelo preconceito racial. [grifos nossos]

Nesse sentido, muitos professores relataram experiências de preconceito racial no seu cotidiano. Seguem alguns exemplos de manifestações flagrantes vivenciadas pelos docentes.

No sul do Brasil, R. e S. C. perceberam que as pessoas preferiam ir de pé em vez de compartilharem o assento do ônibus com eles; e garçons/atendentes se recusavam a servi-los em alguns restaurantes. E R. M. também percebeu nitidamente a discriminação ao ser excluída pelo garçom que servia uma mesa com 20 convidados nessa região do país. A manifestação flagrante do preconceito mencionada por esses professores no sul do Brasil não quer dizer que eles não o sofreram também em outras partes do país, mas que apenas que o citaram como exemplos mais significativos. Da mesma forma,

${ }_{20}$ Ibid, p. 141.

${ }^{21}$ Ibid, p. 161. 
outros docentes citaram espaços e localidades onde sofreram o preconceito de modo mais evidente.

Nessa perspectiva, T. relatou que ficou preso por uma noite em Ouro Preto sem nenhuma acusação e justificativa da polícia. R. mencionou que era barrado inúmeras vezes nas portarias da UFMG quando esquecia o seu crachá de identificação. E L. M. relatou que vivenciou esse tipo de constrangimento em Ouro Preto, ao ser barrada quando foi a um departamento da Universidade Federal de Ouro Preto (Ufop) com um colega branco (que não foi barrado). Ela também afirmou que sofreu todo tipo de discriminação e em todo lugar, por ser mulher e negra, em hotel, loja, elevador.

D. F. contou que já foi "brindado dentro da Universidade com pérolas do racismo", quando um colega disse: "Nossa, você é professor e com esse corpo atlético? Essa cabeça pensa22?”

L. A. relatou que teve dificuldades em ser tratado como igual nas reuniões de coordenação da pós-graduação. E T. S. já foi ameaçado por um aluno, por ser negro, quando da sua posse em um alto cargo da UFMG, e sofreu questionamentos, por parte de alguns colegas, sobre como ele (um negro) poderia representar a Universidade, sendo prejulgado como incapaz intelectualmente de travar uma discussão com indivíduos de outras universidades em cargo equivalente.

Situações como essas relatadas acima demonstram o quanto o preconceito racial ainda está arraigado na sociedade brasileira, derivado de uma longa socialização racista, na qual propagou-se uma suposta inferioridade da raça negra por gerações, através do senso comum e também de teorias ditas “científicas” (SANT’ANA, 2005) com o propósito de dominação e subjugação. Nessa perspectiva,

A desconstrução científica da raça biológica não faz desaparecer a evidência da raça simbólica, da raça percebida e invariavelmente interpretada, porquart̉o raça, queira-se ou não, permanece um elemento maior da realidade social, à medida que emprega, a partir de características físicas visíveis, formas coletivas de diferenciação classificatória e hierárquica que podem engendrar, às vezes, comportamentos discriminatórios individuais ou coletivos (TAGUIEFF, 1995 apud DAHIA, 2008, p. 699).

As normas sociais mudaram, mas é possível que a representação social

22 Ibid, p. 59.

23 TAGUIEFF, P. A. Les fins de l'antiracisme. Paris: Michalon, 1995. 
do preconceito racial ainda reflita o período de exploração do trabalho escravo dos negros, no qual "[...] o racismo era expresso de maneira aberta, pois refletia as normas sociais da época: as normas da discriminação e da exploração" (LIMA; VALA, 2004, p. 403). E como afirma Moscovici (2003, p. 38): “Sob muitos aspectos, o passado é mais real que o presente. 0 poder e a claridade peculiares das representações - isto é, das representações sociais - derivam do sucesso com que elas controlam a realidade de hoje através da de ontem e da continuidade que isso pressupõe".

Mesmo que a realidade desses professores (profissionais pós-graduados e em condições socioeconômicas e educacionais elevadas) contradissesse os conteúdos de representação social relacionados ao preconceito racial, esses conteúdos ainda permanecem vivos e circulando entre os sujeitos, ancorandose em representações do passado acerca dos negros. Nesse aspecto, “[...] a diminuição das expressões do racismo seria mais aparente que real, pois as atitudes preconceituosas que não desafiam abertamente as normas atuais anti-discriminatórias persistiriam no interior das consciências dos indivíduos" (CAMINO et al., 2001, p. 15).

Sobre isso, os docentes narraram situações em que o preconceito racial, apesar de perceptível, podia ser camuflado. Esse tipo de preconceito chama a atenção pela sua ambiguidade, ou seja, ele é identificado, mas não o suficiente para gerar uma reação imediata de denúncia. Seguem alguns dos exemplos narrados pelos professores sobre o preconceito com essas características.

D. F. relatou que notou "reações estranhas" no doutorado no Rio de Janeiro quando os colegas descobriram que o famoso primeiro lugar era um "crioulo" ${ }^{4}$, tanto que fez apenas dois amigos (negros) nesse período. Percebeu também o pouco respeito por parte dos alunos para com um professor negro que não tinha sinais evidentes de prosperidade econômica.

L. M. também relatou alguns casos, dentre eles o de um colega que disse que havia se lembrado dela porque viu alguma coisa sobre literatura africana, que não é a sua especialidade na academia. Ela apontou: "Aí você tem os lugares marcados por você ser negra, as pessoas acham que o seu âmbito de atuação tem que também ser demarcado ${ }^{25}$ ". No cotidiano, ela também observou a hesitação de porteiros quando demonstram não saberem se ela é moradora ou serviçal de um edifício de classe média, considerando que ela era a única moradora negra desse edifício.

Ibid, p. 58.

Ibid, p. 79. 
L. A. relatou que no trabalho, quando era coordenador da pós-graduação de uma das faculdades da UFMG, teve que conquistar espaço, tendo de mostrar que podia fazer determinadas coisas, pois não tinha certeza se as pessoas achavam-no capaz. E noutro setor da Universidade já foi tratado algumas vezes como "aprendiz" por colegas que tentaram ensiná-lo algo sobre a matéria que ele lecionava na Universidade.

R. narrou que além dos barramentos constantes nas portarias da UFMG, observava que em seu crachá a identificação nunca vinha escrita como professor. E T. S. percebia o estranhamento e o burburinho gerado em solenidades quando ele se apresentava. Contou que, certa vez, em um congresso internacional, vieram perguntar a ele, em um café em Viena, se era jogador de futebol ou sambista. Sobre isso ele comentou: “Não é esperado que um negro possa ser um cientista, mas há outras atividades nas quais os negros podem se destacar, e de fato se destacam, como atletas, músicos ${ }^{26 "}$.

Para A. A., manifestações aparentemente sutis ou pequenas podem revelar muito do preconceito. Em sua opinião, há pessoas que avaliam a questão como "paranoia de negro ${ }^{27}$ ", porém foi constante na sua trajetória acadêmica encontrar alguém que colocasse em dúvida a sua função como professora e/ ou diretora. Um dos exemplos citados por A. A. que ilustram essa dúvida entre o fenótipo e o elevado cargo referiu-se a uma situação em que uma moça, ao chegar à sala da direção, questionou-a se era a secretária. Diante da negativa, a moça permaneceu incrédula, riu e ironizou: “Ah, você é diretora ${ }^{28}$ !?”

W. A., quando estudante, podia notar a surpresa das pessoas ao observarem sua vestimenta (simples) e o fato de ele ser aluno da UFMG. Outro episódio inclui M. S., que não se considera vítima do racismo. No entanto, quando ele foi negociar a venda de seu apartamento, percebeu que a compradora estranhou ao saber que ele era professor universitário. Para esse professor, essa particularidade se liga prioritariamente à classe social, no qual o negro é associado à pobreza e à baixa escolaridade pelo senso comum.

Decerto, a sociedade brasileira "[...] desaprova as manifestações flagrantes de estigmatização com base em distinções de cor" (OLIVEIRA; BARRETO, 2003, p. 195). Todavia, isso não significa que tal estigmatização e distinção não sejam praticadas cotidianamente contra as pessoas negras, mesmo que dissimuladamente, como foi possível apreender das falas dos docentes da UFMG.

\footnotetext{
26 Ibid, p. 148.

27 Ibid, p. 29.

28 Ibid, p. 28.
} 


\section{AS REPRESENTAÇÕES SOCIAIS DO PRECONCEITO RACIAL E SEUS CONTEÚDOS}

Os conteúdos que refletiram as situações preconceituosas vivenciadas pelos professores negros da UFMG indicaram a ênfase do espaço social, abrangendo, portanto, a convivência cotidiana, a escola e o âmbito profissional. Não só nas músicas, mas nos ditados populares, anedotas, brincadeiras etc., o emprego de expressões burlescas correspondiam às metáforas divulgadas no dia a dia, figurando o racismo disfarçado na cultura brasileira. Apesar da sutileza, esse fenômeno não excetua a discriminação contra os cidadãos negros, implicando, pois, a total falta de cordialidade nas relações interpessoais.

Por meio da análise das narrativas percebemos que os conteúdos acerca do preconceito racial se ancoravam na muito propagada ideia do nosso passado recente, sobre a inferioridade do negro em relação ao seu referente positivo branco e dos estereótipos que sustentavam/ sustentam a ideologia racista. Como afirmam Cabecinhas e Amâncio (2004, p. 140):

Se hoje em dia poucos ousam defender abertamente uma hierarquia racial, em contrapartida a ideia de raça, no sentido de uma população natural definida por caracteres hereditários comuns, persiste e continua a servir de suporte a ideologias racistas.

Dessa maneira, as formas de manifestação do preconceito racial, mesmo quando se metamorfoseavam em expressões menos óbvias e verificáveis, se ancoravam nesses conteúdos, ainda que suas vítimas, no caso dos docentes, gozassem de condição econômica e status ocupacional privilegiado em comparação ao restante da nossa sociedade. Confirmando o que dizem Oliveira e Barreto (2003, p. 189): “[...] o julgamento negativo e prévio dos membros de uma raça, uma religião ou dos ocupantes de qualquer outro papel significativo, seria mantido apesar de fatos que o contradiriam”.

Nessa perspectiva, relacionando os conteúdos invocados pelos docentes, identificamos a representação social do negro como sujeito de menor valor humano, como fora do lugar em situações de poder e menos capaz intelectualmente. Sobre isso, Camino et al. (2001, p. 26) apontam “[...] elogiase nos negros sua força, seu ritmo, sua sensualidade, sua habilidade nos esportes etc., enquanto se tem como natural a maior presença dos brancos nas estruturas do poder". Isso foi evidenciado nos relatos dos docentes acerca do estranhamento expresso por alguns sujeitos ao serem confrontados com negros em posições sociais elevadas.

Esses conteúdos também remetem aos papéis na sociedade, na qual há lugares demarcados para os negros, sendo esses lugares de caráter subalterno em relação ao branco. Como afirma T. S.: 
Não é estranhável que na televisão apareçam bandidos negros, atletas, cantores, ou mulheres bonitas negras... Tudo isso a nossa cultura aceita, não é estranhável as mulheres ou os homens servindo cafezinho, comida no restaurante ou que façam trabalhos domésticos etc., isso as televisões, as novelas povoam a nossa imaginação com figuras negras nesses papéis, quase sempre papéis subalternos.

Agora, é estranhável sim que apareça na televisão um negro na função de [alto cargo acadêmico]. [ênfases do autor]

E mesmo com o rompimento desses docentes com esses estereótipos, eles continuam sendo acessados nas relações sociais onde o preconceito racial se manifestava, remetendo a representações sociais muito arraigadas, nas quais os negros foram classificados negativamente. Segundo Moscovici (2003, p. 63): “Classificar algo significa que nós o confinamos a um conjunto de comportamentos e regras que estipulam o que é, ou não é, permitido, em relação a todos os indivíduos pertencentes a essa classe”.

Nesse sentido, mesmo com todos os movimentos para a extinção do preconceito racial, esses conteúdos permanecem vivos em nossa sociedade, ainda relacionando a raça negra à inferioridade, sendo necessárias mais iniciativas para a desconstrução dessa representação, assim como mais estudos sobre essa temática, como indicou L. A.: “O que ter negros na universidade, negros na televisão, ainda que poucos, está interferindo nos neurônios das pessoas [...] $]^{30 "}$.

\section{CONSIDERAÇÕES FINAIS}

As análises indicaram que, apesar da proibição legal, o preconceito em função da raça continua existente em nossa sociedade, conforme foi percebido pelos docentes negros da UFMG. Quanto maior o avanço na trajetória escolar e profissional, mais o negro se afastou de sua comunidade e nessa experiência ambivalente, demarcada por exclusão e mérito, a maioria dos professores negros ainda se viu refém do imaginário social que os associavam a inferioridade, marginalidade, subordinação e incapacidade em relação ao branco.

Relacionado ao objetivo desse artigo percebeu-se que o preconceito racial ainda é muito vivo em nossa sociedade e que o sentido dele para os docentes relaciona-se a mecanismos muito eficientes de exclusão social, o que retroalimenta o preconceito, uma vez que busca manter acentuado o desnível

29 Ibid, p. 148.

30 Ibid, p. 86. 
entre brancos e negros e esse desnível é "interpretado" como diferenças “naturais” entre as raças. Os conteúdos permanecem tal qual quando as normas sociais não eram contrárias a sua expressão, demonstrando uma grande habilidade de adaptação para a sua manutenção no senso comum, ao mesmo tempo em que é sustentado um discurso de uma suposta democracia racial no Brasil. 


\section{Social representation of racial prejudice for black teachers at the UFMG}

Abstract: The present article intends to examine the meaning of the racial prejudice for black teachers at the Federal University of Minas Gerais and the social representation's contents such practices relied on. To do so, 16 interviews from the book "Memórias e percursos de professores negros e negras na UFMG" [Black male and female teachers' memories and progress at the UFMG] by Praxedes et al. (2009) were used as research material. Considering present social rules against this prejudice, its presence has been identified in the everyday life of these teachers both explicitly and covertly. It has been verified that while these teachers enjoyed socioeconomic and educational status it wasn't enough to dispense them of facing this practice. The conclusion has been that the illegitimacy of racial prejudice hasn't extinguished its representational contents, still alive and current in Brazilian society.

Key words: Racial prejudice. Social representation. Black teachers. UFMG. 
ARRUDA, Ângela. Despertando do pesadelo: a interpretação. In: MOREIRA, A. S. P. et al. (Orgs.) Perspectivas teórico-metodológicas em representações sociais. João Pessoa: Editora Universitária - UFPB, 2005.

BARDIN, Laurence. Análise de conteúdo. Lisboa: Edições 70, 1977.

BRASIL, Lei no 7.716, de 5 de janeiro de 1989. Disponível em: 〈www.jusbrasil. com.br/legislacao/.../lei-do-crime-racial-lei-7716-89> Acesso em: 9 jan. 2012.

CABECINHAS, Rosa. Representações sociais, relações intergrupais e cognição social. Paidéia, Ribeirão Preto, v. 14, n. 28, p. 125-137, mai./ago. 2004.

; AMÂNCIO, Ligia. Dominação e exclusão: representações sociais sobre minorias raciais e étnicas. Portugal: Universidade do Minho/Centro de Estudos de Comunicação e Sociedade, 2004.

CAMINO, Leoncio et. al. A face oculta do racismo no Brasil: uma análise psicossociológica. Revista Psicologia Política, n. 1, p. 13-36, 2001.

DAHIA, Sandra Leal de Melo. A mediação do riso na expressão e consolidação do racismo no Brasil. Sociedade e Estado, Brasília, v. 23, n. 3, p. 697-720, set./dez. 2008.

ELIAS, Norbert; SCOTSON, John L. Os estabelecidos e os outsiders: sociologia das relações de poder a partir de uma comunidade. Tradução de Vera Ribeiro; tradução do posfácio à edição alemã de Pedro Süssekind. Rio de Janeiro: Jorge Zahar, 2000.

FERNANDES, Florestan. 0 negro no mundo dos brancos. São Paulo: Difel, 1972.

GUIMARÃES, Antônio Sérgio Alfredo. Racismo e anti-racismo no Brasil. São Paulo: Editora 34, 1999.

- Rediscutindo o conceito de raça. In: Classes, raças e democracia. São Paulo, Editora 34, 2002, p. 48-60.

IBGE, Instituto Brasileiro de Geografia e Estatística. Síntese de indicadores sociais: uma análise das condições de vida da população brasileira 2010. Estudos e Pesquisas: Informação Demográfica e Socioeconômica, Rio de Janeiro, v. 27, 2010. 
JODELET, Denise. Representações sociais: um domínio em expansão. In. . (Org.). As representações sociais. Rio de Janeiro: Eduerj, 2002, p. 17-44.

. Loucuras e representações sociais. Tradução de Lucy Magalhães. Petrópolis: Vozes, 2005.

JOVCHELOVITCH, Sandra. Os contextos do saber: representações, comunidade e cultura. Petrópolis: Vozes, 2004.

LIMA, Marcus Eugênio Oliveira; VALA, Jorge. As novas formas de expressão do preconceito e do racismo. Estudos de Psicologia, v. 9, n. 3, p. 401-411, 2004.

MOSCOVICI, Serge. Representações sociais: investigação em psicologia social. 3. ed. Petrópolis: Vozes, 2003.

OLIVEIRA, Cloves Luiz Pereira; BARRETO, Paula Cristina da Silva. Percepção do racismo no Rio de Janeiro. Estudos Afro-Asiáticos, v. 25, n. 2, p. 183-213, 2003.

PEREIRA, Cícero; TORRES, Ana Raquel Rosas; ALMEIDA; Saulo Teles. Um estudo do preconceito na perspectiva das representações sociais: Análise da influência de um discurso justificador da discriminação no preconceito racial. Psicologia: Reflexão e Crítica, v. 16, n. 1, p. 95-107, 2003.

PRAXEDES, Vera Lúcia; TEIXEIRA, Inês Assunção de Castro; SOUZA, Anderson Xavier de; GONZAGA, Yone Maria (Orgs.). Memórias e percursos de professores negros e negras da UFMG. Belo Horizonte: Autêntica, 2009.

SÁ, Celso Pereira de. A construção do objeto de pesquisa em representações sociais. Rio de janeiro: Ed. Uerj, 1998.

SANT'ANA, Antonio Olimpio de. História e conceitos básicos sobre o racismo e seus derivados. In: MUNANGA, Kabengele (Org.). Superando o racismo na escola. Brasília: MEC, 2005, p. 39-68.

SILVA, Ana Celia da. A desconstrução da discriminação no livro didático. In: MUNANGA, Kabengele (Org.). Superando o racismo na escola: Brasília, MEC, 2005, p. 21-38.

TAGUIEFF, Pierre-André. Les fins de l'antiracisme. Paris: Michalon, 1995.

TRINDADE, Zeidi Araújo; MENANDRO, Maria Cristina Smith; GIANÓRDOLINASCIMENTO, Ingrid Faria. Organização e interpretação de entrevistas: 
uma proposta de procedimento a partir da perspectiva fenomenológica. In: RODRIGUES, M. M. P.; MENANDRO, P. R. M. (Orgs.) Lógicas metodológicas: trajetos de pesquisa em psicologia. Vitória: GM Editora, 2007.

VALA, Jorge. Representações sociais - Para uma psicologia social do pensamento social. In:

.; MONTEIRO, Maria Benedicta (Orgs.), Psicologia social. Lisboa: Fundação Calouste Gulbenkian, 1993.

VENTURI, Gustavo; PAULINO, M. F. Pesquisando preconceito racial. In: TURRA, Cleusa; VENTURI Gustavo (Orgs.). Racismo cordial: a mais completa análise sobre o preconceito de cor no Brasil. São Paulo: Ática, 1995, p. 83-95.

RECEBIDO: Agosto de 2013.

APROVADO: Setembro de 2013. 